allergy was diagnosed by a practitioner of alternative medicine, and her symptoms improved transiently when milk was withdrawn from her diet. She was referred six weeks later with recurrent symptoms. Physical examination yielded no unusual results. Sigmoidoscopy showed the characteristic appearances of Crohn's disease of the rectum, confirmed on biopsy. Her symptoms resolved quickly after treatment with sulphasalazine and she remained well.

Case 3-A 57 year old woman developed symptoms of weight loss, easy fatigue, and diarrhoea. She presented to a practitioner of alternative medicine, who diagnosed diabetes mellitus and intestinal candidiasis in addition to an allergy to gluten, milk, and other dietary constituents. No tests were performed on blood or urine, and the diagnosis was based on the "vegatest" in which the subject holds wires connected to a galvonometer adjacent to the suspect food and the electrical response is recorded. Her weight loss continued and she was referred by her general practitioner. Investigations included a duodenal biopsy, which showed subtotal villous atrophy. After treatment with a gluten free diet the appearances of her small bowel biopsy specimens improved, she gained weight, and she remained well on a gluten free diet.

Case 4-In 1981 a 13 year old girl was diagnosed as having anorexia nervosa but declined follow up and treatment. She continued to follow a highly restrictive diet until 1985, when she was seen by a food allergist who diagnosed multiple food hypersensitivity and prescribed an even more restricted diet together with a course of "enzyme potentiated desensitisation," 3 but during this she was admitted to hospital after collapsing at home. She weighed $22 \mathrm{~kg}$ and was hypothermic, unconscious, with bradycardia at 40 beats/min and unrecordable blood pressure. A chest radiography showed bronchopneumonia. She improved with general supportive measures and regained consciousness. Both the patient and her mother were very resistant to any nutritional support and refused any form of food unless this was discussed with the food allergist whom she had consulted before. The patient died five days after admission. The cause of death was bronchopneumonia due to anorexia nervosa.

\section{Comment}

Patients with a variety of symptoms often present to practitioners of alternative medicine and it is likely that food allergy will be diagnosed on the basis of invalid investigations. Many of these patients have functional disorders, such as irritable bowel syndrome, depression, or hyperventilation, ${ }^{4}$ and nutritional deficiencies may result from treatment. ${ }^{5}$ More importantly, incorrect diagnosis and treatment may delay the diagnosis of serious organic disease such as colonic neoplasia, coeliac disease, inflammatory bowel disease, or anorexia nervosa until the disease is advanced, and in two of the patients reported on here this led to death.

Doctors need to be aware that the diagnosis of food allergy is usually incorrect and may obscure readily treatable but potentially lethal conventional diseases.

We thank Dr C A Loehry for permission to report case 4.

1 Robertson DAF, Wright R. Food allergy and intolerance. Clin Gastroenterol 1987;1:473-85

2 Kerr GR, Wu-Lee M, El-Lozy M, et al. Prevalence of the chinese restaurant syndrome f Am Diet Assoc 1979;75:29-33.

3 McEwen LM. Enzyme potentiated hyposensitisation. Ann Allergy 1975;35: 98-103.

4 Rix KJB, Pearson DJ, Bentley SJ. A psychiatric study of patients with supposed food allergy. Br 7 Psychiatr 1984;145:121-6.

5 Hughes M, Clark N, Forbes L, Colin-Jones DG. A case of scurvy. Br Med $\mathcal{F}$ 1986;293:366.

(Accepted 20 May 1988)

\title{
Arterial oxygen tension and saturation in hospital patients: effect of age and activity
}

\section{Harmjo Blom, Margot Mulder, Wim Verweij}

\author{
St Lucas Hospital, \\ Amsterdam, \\ The Netherlands \\ Harmjo Blom, MD, internist \\ Margot Mulder, junior \\ physician \\ Wim Verweij, clinical \\ chemist
}

Correspondence to: $\mathrm{Dr} \mathrm{H} \mathrm{J}$ Blom, Department of

Internal Medicine, St Luca Ziekenhuis, J Tooropstraat 164, 1061 AE, Amsterdam, The Netherlands.
Blood gas concentrations are the result of anatomical, physiological, and physical variables, which are usually age dependent.

About 30000 blood gas analyses are performed each year in a 500 bed hospital. ${ }^{2}$ Owing to the increasing number of elderly patients true reference values related to age would be helpful, but no conclusive studies have been published. Sorbini et al showed a linear relation between oxygen tension and age, ${ }^{3}$ but the numbers of patients aged over 60 in that and other studies were small. . $^{3.5}$

We therefore performed a study to $(a)$ define reference values for oxygen tension and haemoglobin saturation related to age in an inpatient population with a high proportion of elderly people; $(b)$ investigate the effect of bed rest and normal activity on these values; and $(c)$ compare the clinical usefulness of oxygen tension and oxygen saturation measurements.

\section{Patients, methods, and results}

One hundred and eight patients aged 20 to 90 were studied out of 532 consecutive patients admitted for elective surgery. Patients were excluded because of overt cardiac, pulmonary, or metabolic disease; obesity (Quetelet index $>25$ ); or smoking ( $>10$ cigarettes/day). Findings on preoperative assessment, including an electrocardiogram, a chest radiograph, and haematological and biochemical profiles, had to be normal. We obtained informed consent from 117 of 162 suitable patients. After testing six were excluded because of hyperventilation $(\mathrm{pH}>7 \cdot 50$, carbon dioxide tension $<4.20 \mathrm{kPa}$ ) and three because of incomplete data. Blood gas analyses were performed twice. One value was obtained after at least 30 minutes' bed rest and the second value after activity, defined as a walk of at least 100 metres. Brachial or radial arterial blood samples were obtained from the patients in a semirecumbent position with a disposable, pre-heparinised system with a 22 gauge needle (Concord Micropulse). The samples were measured in duplicate within 10 minutes with an ABL-3 blood gas analyser (Radiometer) and a 282-CO oximeter (Instrumentation Laboratory).

Mean arterial oxygen tension differed significantly (Student's $t$ test on paired observations) between rest and activity in those aged $30-50$ years $(11 \cdot 82$ (SD 1.35) v $12.67(1.17) \mathrm{kPa}, \mathrm{n}=31, \mathrm{p}<0.001), 51-70$ years $(10.79(1.23) v 11.44(1.13) \mathrm{kPa}, \mathrm{n}=31, \mathrm{p}<0.01)$, and over 70 years $(10.20(1.0) v 11.11(1.03) \mathrm{kPa}, \mathrm{n}=25$, $\mathrm{p}<0.01$ ), but not in the 21 patients aged under 30 $(13.13(0.81) v 1.33(1.02)$. There were no significant differences between the age groups in arterial oxygen saturation.

The moving averages on the observed arterial oxygen tension and saturation values were calculated from patient data ranked by age; these values are shown in the figure plotted in relation to average ages obtained in the same way. As a moving average is a range of mathematical means a standard deviation can be given for every value on the curve. With respect 
to age the standard deviation ranged from $2 \cdot 2$ to 4.9 years, indicating an even distribution of the patients. The standard deviation of the means ranged from 0.84 to $1.25 \mathrm{kPa}$ for arterial oxygen tension and from $0 \cdot 7$ to $2 \cdot 1 \%$ for oxygen saturation. No clinically important differences were found for other variables (multiple analysis of variance for haemoglobin, packed cell volume, mean cell volume, arterial carbon dioxide tension, bicarbonate concentration, $\mathrm{pH}$, and smoking habits $(<10$ cigarettes/day)). There were no sex differences, except for persistently higher packed cell volumes in men.

\section{Comment}

Most studies of blood gas concentrations have shown a linear decrease in oxygen tension with age. ${ }^{1}$ This would suggest hypoxaemia in advanced age even in the absence of disease, but most of these studies included few patients over the age of 60 .

The findings in our series of healthy inpatients are likely to represent the minimal estimate of the effect of age. Although the arterial oxygen tension declined significantly $(p<0.001)$ with age, this decline was not linear in advanced age. Elderly patients did better, probably following the "survival of the fittest" concept. Minor activity had a pronounced effect on oxygen tension, which was less evident on oxygen saturation because of the $S$ shaped oxygen dissociation curve.

To define hypoxaemia one must rely on normal values related to age and activity. In the elderly determination of the oxygen saturation is helpful in differentiating a normal from a pathological state.

We thank Dr Y S L Heck, Dr Gareth Davies, and Professor L G Thijs for valuable advice, the workers of the admission

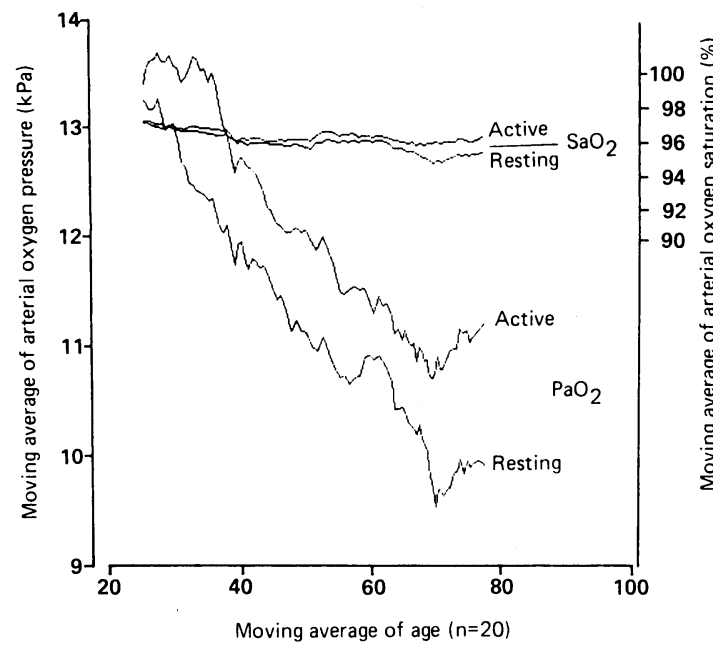

Relation between arterial oxygen tension, arterial oxygen saturation, and age in samples obtained from patients at rest and after activity

desk for their help in selecting the patients, the laboratory workers for their enthusiastic support, and Marion Overhuijs for typing the manuscript.

1 Mahler DA, Rosiello RA, Loke J. The aging lung. Clin Geriatr Med 1986;2: $215-25$.

2 Raffin TA. Indications for arterial blood gas analysis. Ann Intern Med 1986;105:390-8.

3 Sorbini CA, Grassi V, Solinas E, Muiesan G. Arterial oxygen tension in relation to age in healthy subjects. Respiration 1968;25:3-13.

4 Loew PG, Thews G. Die Altersabhängigkeit des arteriellen Sauerstoffdruckes bei der berufstätigen Bevolkerung. Klin Wochenschr 1962;40:1093-8.

5 Ulmer WT, Reichel G. Untersuchungen über die Altersabhängigkeit der alveolaren und arteriellen Sauerstoff und Kohlensäuredrucke. Klin Wochenschr 1963;41:1-6.

(Accepted 12 May 1988)

\section{Occult AIDS: Pneumocystis carinii pneumonia in elderly people}

\author{
M R Hargreaves, G N Fuller, B G Gazzard
}

Department of Medicine, St Stephen's Hospital, London SW10

M R Hargreaves, MRCP, medical registrar GN Fuller, MRCP, medical registrar

B G Gazzard, FRCP, consultant physician

Correspondence to: DrFuller.
The common understanding of AIDS is that it affects young homosexuals and intravenous drug addicts. In a young man presenting with an acute respiratory illness the diagnosis of an infection related to AIDS would be considered. We describe two patients, aged 64 and 73, who presented with chest infections; the diagnosis of AIDS was initially overlooked on the basis of both their age and the history.

\section{Case reports}

Case 1-A previously fit 73 year old bachelor presented with a two week history of increasing breathlessness and dry cough. He denied homosexuality. He was dehydrated and there were bilateral basal crackles. His temperature was normal. His haemoglobin concentration was $129 \mathrm{~g} / \mathrm{l}$ and his white cell count $4.9 \times 10^{9} / 1$ with a normal differential. A chest $x$ ray film showed extensive, predominantly left sided consolidation. Culture of sputum and blood yielded negative results. Titres of antibody to legionella, mycoplasma, coxiella, and chlamydia during the acute and convalescent phases of his illness and results of screening for respiratory viruses were negative. Despite seven days' treatment with ampicillin and erythromycin his condition continued to deteriorate. On further questioning he admitted to having had a few homosexual relationships. After counselling he was tested for human immunodeficiency virus (HIV) antibody; the result was positive. Bronchoscopy with bronchoalveolar lavage and transbronchial biopsy did not show any pathogen. High dose intravenous co-trimoxazole for 14 days produced clinical and radiological resolution, and he was discharged taking oral maintenance treatment with co-trimoxazole. The titre of antibody to Pneumocystis carinii rose from $1 / 32$ to $1 / 128$. He died 18 months later. $P$ carinii was found in the lung at necropsy.

Case 2-A 64 year old man presented with a two month history of increasing breathlessness and dry cough. He had a 10 year history of chronic obstruction of the airways. He had taken amiodarone $200 \mathrm{mg}$ daily intermittently for two months for paroxysmal atrial fibrillation. He was divorced and on admission denied homosexuality. He was centrally cyanosed and dyspnoeic and had a fever $\left(38^{\circ} 5^{\circ}\right)$. His chest was hyperinflated with a poor air entry throughout and no added sounds. His haemoglobin concentration was $166 \mathrm{~g} / \mathrm{l}$ and white cell count $5.6 \times 10^{9} / 1$ with a normal differential. The oxygen tension was $6.7 \mathrm{kPa}$ and the carbon dioxide tension $4.0 \mathrm{kPa}$. A chest $x$ ray film showed diffuse bilateral reticulonodular shadowing, predominantly in the mid and upper zones. Sputum and blood cultures yielded negative results. Titres of antibody to legionella, mycoplasma, coxiella, and chlamydia during the acute and convalescent phases of his illness and results of screening for respiratory viruses were negative. After seven days' treatment with ampicillin his condition deteriorated, and on direct questioning he admitted having had occasional homosexual relationships. After counselling he was tested for HIV antibody and found to be positive. Bronchoscopy with bronchoalveolar lavage and 